ARTIGOS I ARTICLES 



\title{
AVANÇOS ALCANÇADOS POR PROFESSORES NA IMPLEMENTACÃO DA ABORDAGEM TEMÁTICA EM UMA ESCOLA PÚBLICA ESTADUAL DO INTERIOR DO RS
}

\author{
Alexandre Giacomini* \\ Colégio Militar de Santa Maria, Santa Maria (CMSM) - RS, Brasil \\ Cristiane Muenchen ** \\ Universidade Federal de Santa Maria (UFSM), Santa Maria - RS, Brasil
}

RESUMO: O presente artigo, de caráter qualitativo e que utiliza algumas ferramentas metodológicas da etnografia, tem como tema o currículo balizado pela abordagem temática. Buscou-se, neste trabalho, analisar as compreensões e as percepções dos professores de uma escola pública estadual do interior do Rio Grande do Sul acerca dos avanços alcançados quando se implementam intervenções curriculares pautadas pela abordagem temática. O referencial teórico que baliza a pesquisa está alicerçado nos pressupostos do educador Paulo Freire e em ideais das repercussões educacionais do movimento Ciência-Tecnologia-Sociedade (CTS). Os resultados emergiram a partir de uma variedade de instrumentos utilizados na coleta de dados. Mediante a metodologia de Análise Textual Discursiva, foram sintetizados e apresentados sob a forma de categorias de avanços, intituladas de: o tema trabalhado a partir da realidade, do contexto do(s) aluno(s); a mudança na concepção de currículo; e o diálogo entre professor-aluno e aluno-aluno.

Palavras-Chave: Currículo. Abordagem temática. Realidade dos alunos. Diálogo entre professor-aluno e aluno-aluno.

http://dx.doi.org/10.1590/0102-4698136042

*Doutorando do Programa de Pós-Graduação: Educação em Ciências - Química da Vida e Saúde (PPGECQVS) da Universidade Federal de Santa Maria (UFSM), RS. $1^{\circ}$ Tenente do Quadro Complementar de Oficiais (QCO) do Exército e Professor Titular da disciplina de Física do Colégio Militar de Santa Maria (CMSM) - Santa Maria/RS. E-mail: < xandigiacomini@bol.com.br > .

**Doutora em Educação Científica e Tecnológica pela Universidade Federal de Santa Catarina (UFSC). Professora Adjunta da área de Ensino de Física e dos Programas de Pós-Graduação: Educação em Ciências - Química da Vida e Saúde (PPGECQVS) e Educação Matemática e Ensino de Física (PPGEM\&EF) da Universidade Federal de Santa Maria (UFSM), RS. Coordena o Grupo de Estudos e Pesquisas Educação em Ciências em Diálogo (GEPECiD). E-mail: < crismuenchen@yahoo.com.br > . 


\title{
ADVANCES MADE BY TEACHERS IN IMPLEMENTING THEMATIC APPROACH IN A STATE PUBLIC SCHOOL IN RIO GRANDE DO SUL'S COUNTRYSIDE
}

\begin{abstract}
This article, with a qualitative characteristic and some etnographic methodological tools, has as its theme the curriculum marked by thematic approach. We sought in this work to analyze teachers' understandings and perceptions in a state public school in Rio Grande do Sul state's countryside about the advances achieved when implementing curricular interventions guided by the thematic approach. The theoretical referential that guides this research is grounded in the educator Paulo Freire's assumptions and in educational implications's ideals of the movement Science-TechnologySociety (STS). The results emerged from a variety of instruments used in data collection and through the methodology of Textual Analysis Discursive. They were synthesized and presented in advances' categories, entitled: The theme worked from the the student(s) context(s)'s reality; The change in curriculum concept; and Dialogue between teacher-student and student-student.
\end{abstract}

Keywords: Curriculum. Thematic approach. Reality of students. Dialogue between teacher-student and student-student.

\section{INTRODUCุ̃̃O}

Em anos recentes, tem havido um crescente interesse por propostas de intervenções curriculares com perspectivas na focalização de temas de relevância social, ou seja, balizadas na abordagem temática e que busquem a superação dos principais problemas e limitações do contexto escolar. Essas têm sido evidenciadas em diversos estudos (STRIEDER, 2012; CACHAPUZ et al., 2011; DELIZOICOV; ANGOTTI; PERNAMBUCO, 2011; HALMENSCHLAGER, 2011; FERREIRA, 2009; FORGIARINI; AULER, 2009; MUENCHEN, 2006; NASCIMENTO; VON LINSINGEN, 2006; MARTINS, 2003; AULER, 2002; SANTOS; MORTIMER, 2002).

O presente trabalho torna-se relevante pela importância e a necessidade que novas configurações curriculares, baseadas na perspectiva crítica e no contexto social, têm de deflagrar um processo de transformações profundas, abalando o paradigma curricular linear vigente, baseado na divisão do saber e do tempo e dependente de uma prática prescritiva, na qual os programas são resolvidos por instâncias que estão fora da escola e de seu trabalho singular.

À vista disso, visando o contexto supramencionado, emerge o problema de investigação do presente trabalho: Quais são os possíveis avanços alcançados por professores de uma escola pública estadual de Ensino Médio do interior do Rio Grande do Sul quando 
implementam intervenções curriculares na perspectiva da abordagem temática em turmas do Ensino Médio regular e da Educação de Jovens e Adultos (EJA)? A partir dessa questão, apresenta-se o objetivo da pesquisa: analisar as compreensões e as percepções dos professores dessa escola acerca dos avanços alcançados quando se implementam intervenções curriculares pautadas pela abordagem temática.

O referencial teórico que baliza a pesquisa está alicerçado nos pressupostos do educador Paulo Freire, o qual sugere a construção do processo educacional através do que denominou de temas geradores, por meio de uma educação problematizadora, dialógica e que visa à atuação e à transformação social dos homens. Além disso, baseou-se em ideais das repercussões educacionais do movimento Ciência-TecnologiaSociedade (CTS), as quais pressupõem uma educação científica para todos os cidadãos, que favoreça a participação destes na tomada fundamentada de decisões em acontecimentos sociais significativos, no campo econômico, no desenvolvimento tecnológico e científico.

\section{UM NOVO ESTILO DE PENSAMENTO CURRICULAR: DA ABORDAGEM CONCEITUAL PARA A ABORDAGEM TEMÁTICA}

Nos últimos anos, a maior parte das escolas ainda tem adotado um currículo pautado pelo estilo de pensamento (FLECK, 2010) tradicional, ou seja: com uma visão compartimentada, enciclopédica e fragmentada do conhecimento; com situações de aprendizagem que prezam a memorização, descoladas do contexto e da experiência cotidiana dos alunos; com posições de expectação passiva/ contemplativa assumida por professores e alunos; e apresentação dos conteúdos segundo uma abordagem conceitual abstrata. Esses pressupostos, contudo, têm sido verificados por estudos atuais conforme apontam as Orientações Curriculares para o Ensino Médio (BRASIL, 2008, p. 101): “[...] a prática curricular corrente [...] continua sendo predominantemente disciplinar, com visão linear e fragmentada dos conhecimentos na estrutura das próprias disciplinas [...]". Quanto a isso, destaca-se ainda o entendimento de Halmenschlager (2011, p. 11): “[...] ainda são encontradas, em algumas escolas, organizações curriculares descontextualizadas, lineares e fragmentadas, distante das necessidades do aluno de discutir e entender o mundo real no qual está inserido".

De acordo com esses referenciais, Delizoicov, Angotti e Pernambuco (2011, p. 190) caracterizam o currículo vigente como aquele configurado com base na abordagem conceitual: "perspectiva 
curricular cuja lógica de organização é estruturada pelos conceitos científicos, com base nos quais se selecionam os conteúdos de ensino".

Nesse sentido, pode-se inferir que é necessário reavaliar e problematizar a atual questão curricular, que visa ao ensino meramente propedêutico/disciplinar, e buscar um novo estilo de pensamento curricular que vá da abordagem conceitual para a abordagem temática. Esse novo estilo de pensamento curricular pode estar calcado em princípios básicos, tais como a autonomia da escola, o resgate de práticas e experiências avançadas, a discussão e a reflexão coletiva, a unidade da práxis ação-reflexão-ação (FREIRE, 1968, 1987, 1992, 1998), bem como a prática enquanto atividade humana em sua inserção social, conforme defendido por Fleck (2010).

Uma das possibilidades didático-pedagógicas potencialmente promissoras para atender a essa demanda é a organização do programa escolar a partir de temas, ou seja, uma organização curricular balizada na abordagem temática (DELIZOICOV; ANGOTTI; PERNAMBUCO, 2011). Apoiados em Snyders (1988) e Freire (1987), Delizoicov, Angotti e Pernambuco (2011, p. 189) entendem que a proposta curricular que se apoia na abordagem temática pode ser definida como: "Perspectiva curricular cuja lógica de organização é estruturada com base em temas, com os quais são selecionados os conteúdos de ensino das disciplinas. Nessa abordagem, a conceituação científica da programação é subordinada ao tema".

Além de Delizoicov, Angotti e Pernambuco (2011), Muenchen e Delizoicov (2010) e Muenchen (2010) também trata de abordagem temática, diferenciando-a de abordagem conceitual. Segundo esse autor, na abordagem conceitual dá-se ênfase ao conceito científico e, na abordagem temática, vai-se além, pois é dada ênfase ao conceito científico para a compreensão de um tema.

Levando-se em consideração o contexto supramencionado, busca-se a seguir discorrer sobre duas propostas de intervenções curriculares com ênfase na abordagem temática - a de inspiração freireana e a com repercussões educacionais do movimento CiênciaTecnologia-Sociedade (CTS). Ambas são balizadas na utilização de temas/problemas de relevância social no contexto escolar e produzem uma articulação entre os conteúdos programáticos e os temas abordados. Portanto, quando são bem trabalhadas nos espações escolares, as intervenções curriculares produzem ações investigativas e a problematização dos temas estudados, bem como levam o aluno a pensar de forma articulada, contextualizada, e ele passa a ser o protagonista do processo de ensino/aprendizagem. 
A abordagem temática na perspectiva freireana é balizada pelos pressupostos do educador progressista libertador Paulo Freire $(1968,1987,1992,1998)$, o qual é reconhecido como um dos pensadores mais importantes da história da educação em todo o mundo. Esse reconhecimento se justifica por ele ter desenvolvido uma pedagogia para a libertação, segundo a qual é papel da escola formar a consciência política do aluno, através da problematização da realidade, das relações sociais do homem com a natureza e com outros homens, visando à sua atuação e à transformação social.

Embasado numa concepção de educação "problematizadora”, Freire (1987), em sua Pedagogia do Oprimido, propôs a utilização de temas geradores para a elaboração dos programas de ensino. $\mathrm{O}$ conceito de tema gerador, de acordo com Freire (1987, p. 56-57), é:

Os temas, em verdade, existem nos homens, em suas relações com o mundo, referidos a fatos concretos. [...] Há, pois, uma relação entre o fato objetivo, a percepção que dele tenham os homens e os "temas geradores". [...] É através dos homens que se expressa a temática significativa e, ao expressar-se, num certo momento, pode já não ser, exatamente, o que antes era, desde que haja mudado sua percepção dos dados objetivos aos quais os temas se acham referidos.

Por sua natureza, os temas geradores têm, segundo Delizoicov, Angotti e Pernambuco (2011, p. 166), como princípios básicos

Uma visão de totalidade e abrangência da realidade; a ruptura com o conhecimento no nível do senso comum; adotar o diálogo como sua essência; exigir do educador uma postura de crítica, de problematização constante, de distanciamento, de estar na ação e de observar e se criticar nessa ação; apontar para a participação, discutindo no coletivo e exigindo disponibilidade dos educadores.

Os temas geradores são obtidos por meio do processo de investigação temática. Essa, por sua vez, é desenvolvida em cinco etapas, conforme sistematizado por Delizoicov, Angotti e Pernambuco (2011, p. 275), a partir do terceiro capítulo do livro Pedagogia do Oprimido, de Paulo Freire (1987). Resumidamente, essas etapas, que estão em constante interação e se autoalimentam, correspondem a:

- Primeira - "levantamento preliminar": a equipe de educadores coleta materiais sobre o contexto sócio-histórico-econômicocultural em que vivem o aluno e seus familiares, por meio de um trabalho de campo que inclui atividades de visitas a diferentes lugares da redondeza, conversas com moradores e representantes de movimentos sociais.

- Segunda - "codificação": é feita pela mesma equipe de educadores, em função dos dados apreendidos na primeira 
etapa; são escolhidas as situações/contradições mais significativas que expressam a visão da população, em especial, dos alunos e de seus familiares. Nessa etapa, os educadores, a partir de suas formações, procuram entender e analisar as falas da população: o que revelam, o que ocultam, como expressam, refletem ou contrapõem as relações sociais e econômicas em que esses dados e falas são gerados. Só então, alguns temas que poderão vir a ser geradores começam a surgir.

- Terceira - "círculo de investigação temática": consiste na obtenção dos temas geradores a partir da realização de diálogos descodificadores entre professores, alunos, pais e representantes da comunidade; a dinâmica da codificação/ problematização/descodificação é planejada e usada pela equipe de educadores, e finalmente são escolhidos os temas e as situações significativos para a população.

- Quarta - "redução temática": consiste na elaboração do programa e do planejamento de ensino, cujo trabalho se dá por uma equipe interdisciplinar de educadores, com o objetivo de elaborar o programa curricular e identificar/selecionar conteúdos disciplinares bem como conhecimentos que serão necessários para o entendimento dos temas.

- Quinta - "trabalho em sala de aula": os temas são trabalhados pelos professores, que planejam suas atividades interdisciplinarmente; em seguida, discutem com os alunos em sala de aula, apresentando-lhes a lógica do programa elaborado, ainda aberto a mudanças que se façam necessárias.

Certamente esse não é um programa tradicional, a ser seguido à risca, mas um "mapa", constantemente refeito ao longo do percurso, que orienta o trabalho do grupo de educadores, norteando as inúmeras decisões que serão tomadas no dia a dia.

Ressalta-se, todavia, que essa dinâmica da investigação temática rompe com o tradicional paradigma curricular, baseado na abordagem conceitual. De acordo com Muenchen (2010), para responder o questionamento de quais conteúdos científicos deveriam estar ou não na programação de uma disciplina, a estruturação e a articulação da programação, segundo a sistematização supramencionada referente à abordagem temática freireana, seriam critérios a auxiliar as equipes de professores na seleção de quais conhecimentos/conteúdos precisam ser abordados no processo educativo. Desse modo, a identificação dos temas, e não os conceitos, seria o ponto de partida para a elaboração dos programas. 
Logo, é a partir do processo da investigação temática que o professor conhece e interage com a realidade do educando, identificando a forma como este o percebe. Além disso, o processo de investigação temática possibilita a identificação de contradições existenciais, entendidas por Freire (1987) como códigos que precisam ser descodificados e problematizados.

A abordagem temática com repercussões educacionais do movimento Ciência-Tecnologia-Sociedade (CTS) é assim denominada em virtude da terminologia adotada no II Seminário Ibero-Americano Ciência-Tecnologia-Sociedade no Ensino de Ciências (II SIACTS-EC, 2010), realizado em Brasília-DF, no ano de 2010. Na ocasião, o coletivo de pesquisadores sinalizou para a utilização do termo "repercussões educacionais do movimento CTS", como forma de minimização/enfrentamento de um possível processo de esvaziamento do campo face à sua polissemia.

Atualmente, as configurações curriculares construídas a partir desse referencial têm sido evidenciadas em diversos estudos (STRIEDER, 2012; CACHAPUZ et al., 2011; FERRAZ, 2009; MUENCHEN, 2006; NASCIMENTO; VON LINSINGEN, 2006; AULER, 2002; SANTOS; MORTIMER, 2002) e buscam abordar os avanços e as transformações tecnológicas em sua totalidade, discutindo as implicações e as consequências do progresso científico tecnológico no mundo, além dos interesses incorporados nesse processo, bem como procuram contribuir para a formação integral do educando enquanto cidadão consciente das relações CTS e suas influências no mundo contemporâneo.

Os objetivos das repercussões educacionais do movimento CTS no ensino de ciências, segundo Auler $(2007$, p. 1) podem ser sintetizados como

[...] promover o interesse dos estudantes em relacionar a ciência com aspectos tecnológicos e sociais; discutir as implicações sociais e éticas relacionadas ao uso da ciência-tecnologia (CT); adquirir uma compreensão da natureza da ciência e do trabalho científico; formar cidadãos científica e tecnologicamente alfabetizados capazes de tomar decisões informadas; desenvolver o pensamento crítico e a independência intelectual.

Mais recentemente, este mesmo autor (AULER, 2011) tem buscado uma ressignificação das dimensões centrais das repercussões educacionais do movimento CTS, no campo da educação, que passa pela incorporação do Pensamento Latino-Americano em Ciência, Tecnologia e Sociedade (Placts), em ações como: ampliar os mecanismos de participação e discussão de processos decisórios, no contexto não só da pós-produção da ciência e tecnologia, mas 
principalmente da prevenção a priori; bem como contribuir para a constituição de valores democráticos e sustentáveis. Estas ações, por sua vez, estariam diretamente relacionadas à participação no estabelecimento de critérios, de parâmetros para a definição de uma Política Científico-Tecnológica (PCT) (AULER, 2011).

De acordo com Martins (2003, p. 300), as repercussões educacionais do movimento CTS têm assumido uma proposta confiável para orientações curriculares, compreensão de recursos didáticos, bem como para elaboração de estratégias de ensino, capazes de inverter a tendência de desinteresse que os jovens têm apresentado em relação ao ensino das ciências. Em suma, a abordagem temática com repercussões educacionais do movimento CTS possibilita a discussão da relação entre os polos que a sigla aponta e a relevância de aspectos tecnocientíficos em acontecimentos sociais significativos, bem como envolve reflexões no campo econômico e a sua articulação com o desenvolvimento tecnológico e científico.

É importante ressaltar que Auler (2007, p. 13) traçou uma interessante articulação entre os pressupostos das intervenções curriculares pautadas pelas abordagens temáticas supramencionadas. Enquanto, de um lado, Freire propôs a superação da "cultura do silêncio" para alcançar uma "leitura crítica da realidade", do outro, paralelamente a estas, o CTS primou pela superação do modelo de decisões tecnocráticas para almejar uma compreensão crítica sobre interações entre CTS.

As propostas de intervenções curriculares com ênfase na abordagem temática supracitadas estão intrinsecamente ligadas à interdisciplinaridade, uma vez que o trabalho com temas/problemas de relevância social requer a análise de vários olhares disciplinares articulados para respondê-los e solucioná-los.

Nesse sentido, é nos Parâmetros Curriculares Nacionais (BRASIL, 1999) que a interdisciplinaridade ganha dimensões marcantes ao se propor uma reorganização curricular em áreas do conhecimento, com o intuito de facilitar o desenvolvimento dos conteúdos e a contextualização. A interdisciplinaridade, vista enquanto uma ciência em processo de construção, busca o diálogo e a troca de ideias entre os especialistas das diferentes áreas do conhecimento. Assim sendo, as Orientações Curriculares para o Ensino Médio (BRASIL, 2008, p. 52) salientam que:

Não basta uma justaposição de várias disciplinas para atingir a competência crítico-analítica [...]. Trata-se da construção de um novo saber a respeito da realidade, recorrendo-se aos saberes disciplinares e explorando ao máximo os limites e as potencialidades da cada área do conhecimento. 
É importante destacar que, para a escola vivenciar uma ação educativa mais produtiva e propiciadora de momentos de interdisciplinaridade, é necessário o trabalho coletivo dos educadores na escola, já que esta prática deixa de ser uma agregação de falas isoladas para ser um conjunto de falas em torno de eixos comuns (SÃO PAULO, 1990).

\section{ENCAMINHAMENTO METODOLÓGICO}

O presente trabalho tem viés qualitativo (GÜNTHER, 2006), quanto ao método e à forma; descritivo e explicativo (GIL, 2007), quanto ao objetivo; e é uma pesquisa qualitativa que utiliza algumas ferramentas metodológicas/procedimentos da etnografia (MARCONDES; ACOSTA, 2006), quanto aos procedimentos adotados na coleta de dados, no caso, a observação participante.

Os instrumentos utilizados na coleta de dados foram: um questionário inicial, a fim levantar os possíveis avanços/contribuições do trabalho com abordagem temática; a observação participante, ocorrida ao longo de toda a pesquisa, por meio de registros e diários de bordo do pesquisador (ou diários de campo); a entrevista semiestruturada, a qual foi aplicada ao término do ano letivo e após a implementação dos temas trabalhados pelos professores; e a análise documental, ou seja, de alguns dos planejamentos e dos materiais didáticos (trabalhos e atividades de avaliação) usados pelos professores na construção coletiva da temática e que seriam aplicados aos alunos.

A metodologia de análise de dados utilizada foi a Análise Textual Discursiva (MORAES; GALIAZZI, 2007), uma metodologia de caráter qualitativo, pois se trabalhou com materiais textuais escritos, como as transcrições de entrevistas, os questionários, os registros da observação participante e os materiais coletados na análise documental.

A presente pesquisa foi realizada numa escola pública estadual do interior do Rio Grande do Sul, envolvendo professores do Ensino Médio regular e da Educação de Jovens e Adultos (EJA) durante o ano de 2012. A referida escola, que funciona apenas com o Ensino Médio - regular e EJA -, tem aproximadamente 620 alunos e conta com 35 professores e 20 funcionários (entre secretaria, limpeza e merenda).

Como a pesquisa tratou da implementação da abordagem temática na prática educativa dos educadores dessa escola, foi necessário dar suporte teórico-metodológico aos docentes. Isso, por sua vez, fomentou a construção de um processo formativo e coletivo 
com o intuito de produzir projetos interdisciplinares com enfoque na abordagem temática. Esse processo de formação se iniciou em meados de julho de 2012, envolveu todos os professores da escola durante uma manhã e uma tarde e contou com um aporte teórico que está em consonância com o referencial teórico defendido neste trabalho. A culminância foi a construção coletiva de uma proposta didático-pedagógica para um trabalho interdisciplinar cuja temática "O Cultivo do Arroz" - já havia sido iniciada na disciplina de física no mesmo ano. A proposta fez parte de um trabalho que se encontra publicado nos Anais do II Seminário Internacional de Ensino de Ciências - SINTEC (GIACOMINI; MAGOGA; MUENCHEN, 2012) e em um número extra da revista Enseñanza de Las Ciencias (GIACOMINI; MUENCHEN; MAGOGA, 2013).

O processo formativo inicial não foi algo estanque, mas apenas o "pontapé inicial" para desencadear o aprofundamento das várias questões propostas, necessário para o acompanhamento da implementação da ação pedagógica na escola. Nesse sentido, a continuidade ocorreu ao longo do ano, nas reuniões quinzenais por área de conhecimento e mensais com o coletivo de professores. É necessário frisar, contudo, nesse processo formativo permanente e continuado, a metodologia dialógica utilizada entre professores, supervisão, orientação, gestão, comunidade escolar e pesquisador na construção e na implementação das temáticas, garantindo, dessa forma, os ajustes necessários de cada área do conhecimento e sua mediação com a realidade estudada, bem como na análise, na interpretação, no comunicado e na socialização das informações no trabalho coletivo e interdisciplinar.

A forma de seleção dos participantes característica do presente trabalho configurou-se de modo intencional, pois o número de professores escolhidos ocorreu propositalmente, em função da relevância que eles representavam em relação a uma determinada etapa da pesquisa. Sendo assim, num primeiro momento, utilizaramse o questionário e a observação participante com todos os professores integrantes do processo formativo, a fim de levantar impressões iniciais a respeito dos possíveis avanços de se trabalhar com abordagem temática; num segundo momento, utilizaramse a observação participante e a análise documental com aqueles professores que seriam foco na pesquisa, quer dizer, os educadores do primeiro ano do Ensino Médio regular e os da EJA, nos três anos; e, finalmente, utilizou-se a entrevista semiestruturada para refinar e aprofundar os dados coletados nas etapas anteriores. 
A entrevista ocorreu com oito professores, caracterizados no Quadro 1, apresentado abaixo, e teve, em média, duração entre 20 e 30 minutos com cada um. Essas entrevistas foram gravadas, com a autorização dos professores, e, posteriormente, transcritas.

QUADRO 1 - Caracterização dos professores entrevistados

\begin{tabular}{|c|c|c|c|c|}
\hline Prof. & $\begin{array}{l}\text { Carga horária } \\
\text { semanal }\end{array}$ & $\begin{array}{l}\text { Disciplina que } \\
\text { leciona }\end{array}$ & $\begin{array}{l}\text { Modalidade de } \\
\text { ensino em que } \\
\text { atua }\end{array}$ & $\begin{array}{l}\text { Tempo de } \\
\text { magistério }\end{array}$ \\
\hline 1 & $40 \mathrm{~h}$ & Filosofia & Regular e EJA & 14 anos \\
\hline 2 & $20 \mathrm{~h}$ & Sociologia & Regular & 4 anos \\
\hline 3 & $37 \mathrm{~h}$ & Geografia & Regular & 5 anos \\
\hline 4 & $33 \mathrm{~h}$ & História & Regular & 3 anos \\
\hline 5 & $20 \mathrm{~h}$ & $\begin{array}{l}\text { Português e } \\
\text { Literatura }\end{array}$ & Regular e EJA & 15 anos \\
\hline 6 & $20 \mathrm{~h}$ & Biologia & Regular e EJA & 18 anos \\
\hline 7 & $32 \mathrm{~h}$ & Artes & Regular e EJA & 6 anos \\
\hline 8 & $40 \mathrm{~h}$ & Biologia & Regular & 24 anos \\
\hline
\end{tabular}

Fonte: Elaboração pelos autores deste artigo. 
Os critérios usados para a escolha desses oito professores foram: ter participado do processo formativo inicial, ter implementado alguma temática e estar participando efetivamente das reuniões coletivas como colaborador do processo interdisciplinar para alavancar o processo de mudança de estilo de pensamento (FLECK, 2010) curricular - da abordagem conceitual para a abordagem temática.

O processo de escolha dos temas, tanto nas turmas de primeiro ano do Ensino Médio quanto nas turmas da EJA, configurou-se por meio de uma adaptação da dinâmica de investigação temática proposta por Freire (1987) e sistematizada em cinco etapas por Delizoicov, Angotti e Pernambuco (2011). Desse processo, emergiram os temas apresentados, conforme apresentado no Quadro 2, a seguir:

QUADRO 2 - Temas definidos e implementados nas turmas do regular e da EJA

\begin{tabular}{|c|c|c|c|}
\hline Turma & Ano & $\begin{array}{c}\text { Modalidade } \\
\text { de Ensino }\end{array}$ & Tema \\
\hline 101 & $1^{0}$ & Regular & Inclusão social no município $X^{1}$ \\
\hline 102 & $1^{0}$ & Regular & Drogas no município de $X$ \\
\hline 103 & $1^{0}$ & Regular & $\begin{array}{l}\text { As implicações sociais, econômicas e culturais do cultivo do } \\
\text { arroz no município de X }\end{array}$ \\
\hline 104 & $1^{0}$ & Regular & Violência familiar: um olhar sobre a realidade $X$ \\
\hline 105 & $1^{0}$ & Regular & $\begin{array}{l}\text { Educação: uma reflexão necessária sobre a importância do } \\
\text { Ensino Médio Politécnico na escola Y² }\end{array}$ \\
\hline 106 & $1^{0}$ & Regular & X: urbanização e seus problemas \\
\hline 107 & $1^{0}$ & Regular & A reciclagem no município de $X$ \\
\hline 108 & $1^{0}$ & Regular & Desemprego: causas e consequências no município de $X$ \\
\hline $\mathrm{T7}$ & $1^{0}$ & EJA & Maus-tratos aos animais do município de $\mathrm{X}$ \\
\hline T8 & $2^{0}$ & EJA & 0 lixo no município $X$ \\
\hline T9 & $3^{0}$ & EJA & Desemprego no município de $X$ \\
\hline
\end{tabular}

Fonte: Elaboração pelos autores deste artigo. 
É importante salientar que os temas definidos e implementados estão presentes na realidade/contexto do município e por isso poderiam ser chamados de "temas geradores", de acordo com a abordagem temática freireana, além de, no processo de escolha, articularem uma adaptação do processo de investigação temática. Destaca-se, além do ressaltado acima, que esses temas abarcam questões sociais, científicas, tecnológicas e de cidadania e, portanto, também têm uma estreita ligação com a abordagem temática com repercussões educacionais do movimento CTS.

\section{RESULTADOS E DISCUSSÃO}

Os resultados emergiram a partir de uma variedade de instrumentos de pesquisa utilizados na coleta de dados e, mediante a metodologia de Análise Textual Discursiva (MORAES; GALIAZZI, 2007), foram sintetizados e apresentados sob a forma de três categorias, as quais constituem os avanços alcançados pelos professores na implementação de intervenções curriculares pautadas pela abordagem temática e sinalizam respostas ao problema de investigação do presente trabalho - Quais são os possíveis avanços alcançados por professores de uma escola pública estadual de Ensino Médio do interior do Rio Grande do Sul quando implementam intervenções curriculares na perspectiva da abordagem temática em turmas do Ensino Médio regular e da Educação de Jovens e Adultos (EJA)? -: o tema trabalhado a partir da realidade, do contexto do(s) aluno(s); a mudança na concepção de currículo; e o diálogo entre professor-aluno e aluno-aluno.

\section{O tema trabalhado a partir da realidade, do contexto do(s) aluno(s)}

Esta categoria emergiu desde as primeiras reuniões pedagógicas, quando os professores relataram a importância de a temática escolhida estar relacionada à realidade dos alunos, como se pode observar em alguns relatos anotados nos diários, representativos do conjunto:

[...] partir da realidade do aluno é um avanço porque desperta nele uma maior participação e interesse pelos estudos. (Prof. 2)

[...] nossos temas terão maior comprometimento por parte dos alunos se buscarmos relacioná-los a seu contexto politico, social e econômico. (Prof. 5)

Em concordância com esses relatos, o trabalho com o cotidiano e com a realidade social, política e econômica dos alunos está relacionado com a prática pedagógica de Paulo Freire (1968, 1987, 1992, 1998), o qual se fundamenta na ideia de que o ensino pode ser trabalhado tirando 
proveito da própria localidade/realidade do aluno. Além do mais, deve haver uma ligação entre o que a escola "dita" e a realidade do estudante, caso contrário, o ensino não terá significado algum.

Também se pode constatar, por meio da análise documental, o forte interesse de alunos, pais e comunidade escolar pelos temas relacionados à sua realidade, entre os quais, vários em cujo título consta a ligação com o município de X, ou seja, fazem alusão ao meio/contexto onde vivem, por exemplo: "As implicações sociais, econômicas e culturais do cultivo do arroz no município de X" (turma $103,1^{\circ}$ ano do Ensino Médio) e "Relação entre os animais soltos e o lixo no município X" (totalidade 8, turma de EJA).

Nesse sentido, as palavras de Delizoicov, Angotti e Pernambuco (2011, p. 292) ratificam a importância de o tema estar ligado à realidade local do aluno:

[...] à escolha do tema está ligada uma compreensão, um estudo efetivo da realidade local, tanto no que ela tem de vivencial - partilhado pelos alunos e pelos grupos sociais a que pertencem - quanto nas relações que permitem estabelecer com a estrutura social vigente.

Essas ideias encontram respaldo em algumas respostas dadas pelos professores no questionário aplicado durante o curso de formação. Entre elas, podem-se citar as seguintes manifestações, representativas do conjunto:

Conseguiremos [professores] êxito na nossa prática com as temáticas ao trabalharmos contextualizando com a realidade do aluno. (Prof. 1)

A articulação dos temas com o mundo real dos alunos vai facilitar nosso trabalho. (Prof. 8)

De acordo com isso, Auler (2007) diz que o ponto de partida para o processo de ensino/aprendizagem deve ser caracterizado por situações-problema, de preferência, relativas a contextos reais e que estejam ligadas ao "mundo vivido" dos alunos.

Aprofundando esta categoria, na entrevista foi possível perceber que uma expressiva parte dos professores falou da relevância de o tema ser trabalhado a partir da realidade, do contexto do(s) aluno(s), como se pode observar nos excertos abaixo, representativos do conjunto:

[...] o tema, ele é muito bom quando é trabalhado com a realidade dos alunos, [...] eles se depararam com essa realidade no momento em que tinham que chegar na prefeitura, na Corsan, na usina, nas propriedades do interior e nas instituições sociais como igrejas e CTGs [Centros de Tradições Gaúchas] para realizar sua pesquisa [...]. (Prof. 2)

[...] com certeza é muito mais gratificante trabalhar a partir da realidade deles [alunos], [...] a bagagem que os alunos trazem do seu cotidiano nos auxilia na construção dos temas trabalhados e gera um maior interesse por parte deles, [...] assim, eles correm atrás e, até, se surpreendem 
com alguns dos resultados, como por exemplo ao trabalhar o tema prostituição como profissão, as meninas achavam, né, que o contexto era um e, a partir da entrevista que elas fizeram, da realidade que puderam vivenciar, concluiram que, na verdade, aquele tipo de vida, aquele tipo de profissão, não era tão gratificante, assim, como imaginavam [...]. (Prof. 3)

[...] quando nós focamos na realidade do aluno, nós proporcionamos um significado maior. [...]. Ele vivencia aquilo, ele vive aquilo, ele é um protagonista. Quando o aluno se sente protagonista, quando ele se apodera de uma realidade, de um contexto de estudo que ele vai fazer, isso tem mais significado para ele. [...] Todo embasamento teórico que nós temos nos nossos livros didáticos, no material que os professores preparam, nos textos complementares, ele ganha significado a partir do momento que o aluno aproxima isso com a realidade que ele vive, porque, não fica uma coisa "estanque", não fica uma coisa mecanizada, tem uma certa bumanidade. [...] Eu acho que é necessário trabalhar a realidade do aluno, fazer o aluno trazer as suas vivências e, aproximar essa vivência de todos os embasamentos teóricos das diversas disciplinas que eles têm. Isso vai gerar um ambiente de aprendizagem atrativo, o aluno vai se empolgar, ele vai buscar mais coisas, ele vai aprender mais [...]. (Prof. 4)

[...] essa prática de trabalhar com o contexto do aluno, como eu te falei no início, não vinha sendo feita por causa de certos receios, mas depois en gostei muito, porque, às vezues, a gente fica falando de determinados assuntos da Biologia que ocorrem em outros países, em desertos, [...] e, tá sempre, lá, [...] é um continente "a", "b", "c", é outro país e, aqui? [...] desta forma, resolvi me aproximar da realidade dos alunos e comecei a ver que eles se interessaram bem mais, principalmente quando trabalhamos o tema poluição daquela sanga, que tem ali perto do correio, [...] os alunos com mais idade me disseram que tomavam banho ali e, boje, não dá pra botar o pé lá dentro, porque tu pode pegar uma infecção por bactérias, ou seja, é muito lixo. [...] assim, quando surgiu uma situação do município, aí, todo mundo se interessou, porque é uma coisa que tá aqui, é real, a gente tá vendo todo dia [...]. (Prof. 6)

Depreende-se, a partir dos excertos acima, que a maioria dos professores conseguiu perceber a relação intrínseca entre a abordagem temática e a realidade do aluno. Ficou evidente, nos depoimentos dos educadores participantes, essa relação, principalmente quando eles apontavam aspectos e ações positivas para a melhoria do processo de ensino/aprendizagem, por exemplo: maiores participação e interesse por parte dos alunos; um ambiente de aprendizagem mais atrativo e significativo para o educando, tornando-o protagonista de sua realidade; transição do ensino de "estanque" para humanizado, pois aproximou a realidade da prática; e contribuição na construção dos temas trabalhados.

Ressalta-se também, nesses excertos, o quanto os professores valorizavam a contribuição dada pelos alunos à escola. Portanto, foi possível perceber que ficou evidente para os educadores que o ponto de partida da prática educativa era a compreensão do mundo em que o educando vive.

Essas evidências também podem ser confirmadas por meio da análise documental, quando, por exemplo, na temática da totalidade 8 da EJA - O lixo no município $\mathrm{X}^{3}$-, aparecem, nas questões 
norteadoras da problematização inicial, relações que fazem alusão ao contexto/realidade do município, como:

\author{
Qual o destino final do lixo no município? \\ O que pode ser feito pela população para diminuir o acúmulo de lixo em sangas, rios, açudes e \\ barragens do municipio? \\ De que forma o lixo pode ser reaproveitado? \\ Existe coleta seletiva no município? Você sabe dizer como ela funciona? \\ Quais as consequências do lixo sem destino inadequado no nosso município?
}

(Análise documental)

No que tange a isso, as palavras de Watanabe-Caramello e Strieder (2011, p. 600) demonstram a importância de trabalhar com a realidade dos alunos:

[...] torna-se necessário conhecer os alunos e a realidade na qual se encontram, buscando, a partir disso, situações significativas para eles e sua comunidade. Essas situações, além de contraditórias, precisam desafiar os alunos a conhecer mais e, ao mesmo tempo, a atuar para transformar a realidade em discussão.

Corroborando nesse sentido, Lucatto e Talamoni (2007, p. 390-396), ao apresentarem "uma proposta de construção coletiva de conhecimentos didático-pedagógicos", referente a um trabalho interdisciplinar em Educação Ambiental que abarcava o tema gerador "a dimensão ambiental da microbacia do Ribeirão dos Peixes", frisam a relevância do tema por representar "uma questão real, contextualizada, presente na vida dos participantes do processo".

Também nas palavras de Martins e Paixão (2011, p. 148) os contextos da vida real são ressaltados na educação CTS:

De fato, nos consensos crescentes acerca da educação CTS como aspecto
indispensável e privilegiado para a integração dos cidadãos no mundo científico
e tecnologicamente sustentado e dependente, os contextos da vida real, [...]
próximos dos alunos, são sempre relevados.

Portanto, ressaltou-se nesta categoria a importância da abordagem temática articular-se ao contexto/mundo em que os alunos vivem, todavia, para que isso se torne uma realidade é necessária uma renovação no currículo linear vigente, foco da próxima categoria.

\title{
A mudança na concepção de currículo
}

Esta categoria emergiu a partir do momento que os professores, tanto do primeiro ano do Ensino Médio regular como da EJA, deramse conta de que era necessária uma reformulação no currículo. Sendo 
assim, demonstraram que aquela "grade de conteúdos" que já vinha elaborada e pensada por uma dúzia de "iluminados" já não servia mais, pois essa mudança curricular deveria vir acompanhada de um processo substancialmente democrático, com a participação de toda a comunidade escolar, em que os conteúdos seriam meios, e não fins para a efetiva implementação da abordagem temática.

Para exemplificar o exposto acima, mostra-se a seguir um exemplo de planejamento, conforme coleta da análise documental, em que o coletivo de professores, de forma democrática, foi o autor do seu próprio currículo, configurando, assim, uma mudança na forma de pensá-lo e fazê-lo. Esse planejamento, construído a partir da temática "Desemprego no município de $\mathrm{X}^{4}$ ", foi balizado pela dinâmica dos Três Momentos Pedagógicos (DELIZOICOV; ANGOTTI; PERNAMBUCO, 2011; MUENCHEN, 2010) e implementado na totalidade 9 da EJA, o que configura uma nova reformulação curricular.

Problematização inicial:

- A tecnologia pode eliminar empregos? Justifique.

- Os robôs e computadores podem substituir o homem? Justifique.

Organização do conbecimento:

Área das Ciências da Natureza:

- A substituição da mão de obra bumana pelas máquinas;

- Saúde do trabalhador.

Área das Ciências Humanas:

- Reflexão acerca do atual sistema mundial (capitalismo, neoliberalismo, globalização, competitividade);

- Tempo da escravidão no Brasil e sua relação com o desemprego;

- Produção do espaço geográfico;

- Leis que abarcam os direitos e os deveres dos trabalhadores;

- Ética e postura do trabalhador;

Área da Matemática e Suas Tecnologias:

- Construção de gráficos comparativos sobre:

- A oferta de empregos no município;

- O nivel de ensino minimo exigido para os empregos que o município oferece;

- O número de pessoas que procuram por emprego na cidade desde o início do ano (pesquisar na ACI [Associação de Comércio e Indústria]).

Área das Linguagens:

- Leitura e produção de textos sobre o tema "desemprego";

- Análise e interpretação de músicas que retratam o tema "desemprego". 
Aplicação do conhecimento:

- Retomada das questões propostas na problematização inicial e outras atividades desenvolvidas, como:

- Pesquisar as causas e as consequências do desemprego no município;

- Entrevistas e depoimentos de pessoas que sofrem com o desemprego no município;

- Entrevista com profissionais liberais que atuam em diferentes setores do município;

- Pesquisar em agências de emprego as principais características exigidas, bem como a documentação mínima necessária para conseguir um emprego.

(Análise documental)

Para Pérez Gómez (1998, p. 376), “transforma-se a prática ao se modificar [sic.] os participantes e a situação", num processo intenso de ação e reflexão, ou seja, a prática do ensino será transformada “ao se modificar [sic.] o currículo e o contexto" (PÉREZ GÓMEZ, 1998, p. 377). Percebe-se nas palavras desse autor a preocupação com a mudança de currículo, e, para que isso aconteça, ele se apoia no trabalho de Freire para propor quatro questões que nortearão esse processo de mudança: "1. Descrever... O que faço? 2. Informar... O que significa o que faço? 3. Confrontar... Como cheguei a ser como sou? 4. Reconstruir... Como posso fazer as coisas de modo diferente? (PÉREZ GÓMEZ, 1998, p. 377).

Em consonância com isso, ao revisar as anotações dos diários de bordo/campo, uma chamou atenção: "Nossa prática sofrerá profundas mudanças quando nós [professores] conseguirmos trabalhar com um currículo mais aberto e flexível, que esteja inserido num contexto social e que atenda às necessidades dos alunos (Prof. 4)".

No que tange a isso, citam-se as palavras de Sampaio, Quadrado e Pimentel (1994, p. 57-58) relatadas sobre o Projeto Interdisciplinaridade no Município de São Paulo, ocorrido entre 1989 e 1992, que visava a uma profunda mudança na concepção curricular linear vigente, conforme descrito:

[...] Propõe-se como meta construir, a partir da sala de aula e da escola, um novo currículo, baseado num outro paradigma, numa perspectiva crítica. Isto implica situar o próprio currículo no contexto social [...]. A mudança de postura com relação ao "pensar e fazer currículo" rompe com o convencional [...] instalando condições para que professores, equipes técnicas, pais e alunos tornem-se partícipes no processo de pensar e fazer currículo, [...] de modo reflexivo e crítico, integrando teoria e prática.

Nessa ideia de buscar uma reconfiguração curricular balizada numa perspectiva crítica que esteja situada no contexto social e que supere o atual currículo linear vigente, também se cita uma manifestação de professor ressaltada no questionário aplicado logo após o curso 
de formação: "A temática foi possível, pois abandonamos o currículo fechado e linear para trabalhar com um currículo mais aberto e flexível, ou seja, organizamo-lo de forma que cada professor pudesse adaptar seu conteúdo àquele tema e naquele momento (Prof. 7)".

Nesse sentido, Delizoicov, Angotti e Pernambuco (2011, p. 189), ao citarem os educadores Paulo Freire (1978) e George Snyders (1988) e seus referenciais baseados em temas, defendem o rompimento do tradicional paradigma curricular, cujo princípio estruturante é a "conceituação científica", para um currículo baseado em temas, ou seja, na "abordagem temática". Assim, esses autores afirmam que é preciso

[...] compreender melhor o porquê da necessidade da estruturação curricular mediante a abordagem temática, que inclua situações significativas para os alunos, em vez de uma estrutura curricular que se organize apenas na perspectiva da abordagem conceitual. (DELIZOICOV; ANGOTTI; PERNAMBUCO, 2011, p. 193)

Aprofundando esta categoria, nas entrevistas depreendeuse que a grande maioria dos professores percebeu que houve uma mudança na concepção curricular, ou seja, o currículo estava mais aberto e flexível, principalmente devido ao trabalho com a abordagem temática. Nesse sentido, citam-se alguns excertos de professores, representativos do conjunto:

[...] Me parece, que a mudança do curriculo na EJA, ela é importante. Está sendo positiva [...] Hoje, parece que ele [currículo] é muito mais aberto, assim, mais amplo, pelo menos, eu sinto, assim. [...] acho ele [currículo] muito mais flexivel, agora. De um lado, é ótimo, porque você não fica preso, né? A uma sequência de conteúdos, "a", "b", "c", e sim, elenca aqueles necessários para trabalhar com o tema em destaque [...] (Prof. 1).

[...] Na verdade, a gente vem há muitos anos com uma estrutura, assim, de gavetas, né? As famosas gavetinhas [...] No mundo de hoje, com toda essa evolução que a gente teve em todas as áreas, ah... Não dá mais pra ficar numa sala de aula, com os alunos como bá trinta anos atrás. [...] a gente tem que mudar... mudar de currículo ah... isto é possivel com a abordagem temática como a gente vem fazendo. Ela [mudança de currículo] épossivel, porque dai a gente sai só daquele curriculo fechado, que a gente olha numa só direção, e tu abre um leque de novos horiz̧ontes, né? Então, eu acho que o caminho é por aí: ter um currículo mais aberto e flexivel [...] (Prof. 6).

[...] Ele [tema] desconstrói, pra reconstruir de uma forma muito melhor. Eu acredito que o tema faça isso. [...] Quando todas as partes se envolvem e trabalham, e, quando a gente, tá aberto a mudanças, mesmo, a essas idas e vindas [busca de conteúdos em outras séries ou totalidades], aí se percebe que a mudança de curriculo é significativa e importante, pois trabalbando com temas estamos rompendo o tradicional currículo linear e fechado que temos [...] (Prof. 7).

Observa-se, a partir dos excertos acima, que a maioria dos professores dessa escola conseguiu perceber e vivenciar essa mudança na concepção de currículo. Isso ficou evidenciado pelos seguintes apontamentos: currículo mais aberto e flexível; currículo que não fica 
preso a uma sequência de conteúdos; currículo que elenca os conteúdos necessários para trabalhar com as temáticas; a mudança no currículo foi possível graças à abordagem temática; currículo como um leque de novos horizontes; currículo caracterizado pelo movimento de busca de conteúdos em outras séries ou totalidades. É importante salientar que esse conjunto de mudanças no currículo não foi esquecido, não caiu no vazio, pois a escola, na maioria das vezes, promoveu a internalização de significados e as condições favoráveis a essa mudança contando com a efetiva participação de professores, alunos, pais e funcionários.

Dessa forma, pode-se inferir que o currículo dessa escola foi marcado por intencionalidades, ainda que pontuais, e não como um espaço neutro, além de uma incorporação crítica, tal como defende Auler (2011, p. 94) ao discorrer sobre os novos caminhos para a educação CTS.

Não se pode esquecer que essa mudança curricular foi fruto dos temas trabalhados pelos professores, tanto no primeiro ano do Ensino Médio regular ("A inclusão social no município X"; "Drogas no município de X"; "As implicações sociais, econômicas e culturais do cultivo do arroz no município de X"; "Violência familiar: um olhar sobre a realidade X"; "Educação: uma reflexão necessária sobre a importância do Ensino Médio Politécnico na Y"; "X: urbanização e seus problemas"; "A reciclagem no município de X"; "Desemprego: causas e consequências no município de X"), como na EJA ("Maustratos aos animais do município de X"; "O lixo no município X"; "Desemprego no município de X"), conforme mostrado no Quadro 2.

Nesse sentido, busca-se nas implementações curriculares pautadas pela abordagem temática um currículo que tenha como princípio o destacado por Freitas (2008) - no seu estudo sobre a organização curricular por ciclos de formação na Escola Cidadã em Porto Alegre, na década de 90 -, que diz:

O currículo deve buscar uma proposta político-pedagógica progressista, voltada para as classes populares na superação das condições de dominação a que estão submetidas, propiciando uma ação pedagógica, dialética, onde se efetive a construção do conhecimento e a relação entre aprendizagem e desenvolvimento, pela comunidade escolar, tanto da(o) professora(or), da(o) aluna(o), quanto do(a) $\mathrm{pai} / \mathrm{mãe}$ e da(o) funcionária(o), através de uma atitude interdisciplinar, viabilizada pela "curiosidade científica", de forma: dinâmica, criativa, crítica, espontânea, comprometida, autônoma, contextualizada, investigativa, prazerosa, desafiadora, original, lúdica. (FREITAS, 2008, p. 65)

Quanto a isso, Muenchen (2010, p. 114), ao discorrer sobre as modificações produzidas pela implementação dos Três Momentos Pedagógicos na Guiné-Bissau, reforça que uma das principais mudanças ocorridas naquele projeto foi a concepção curricular, em 
que "outras disciplinas eram contempladas na sua articulação com as demandas de intervenções no setor produtivo agrícola no qual os alunos atuavam". Desse modo, sua ideia está em consonância com a pretensão desta categoria.

Em suma, a modificação curricular nessa escola aconteceu principalmente na concepção por parte dos professores, tanto os do primeiro ano do regular como os da EJA, pois seus saberes e suas práticas mostraram-se favoráveis a essa mudança e estiveram em consonância com as duas propostas de intervenção curricular almejadas nesta pesquisa: a abordagem temática de inspiração freireana e a abordagem temática com repercussões educacionais do movimento Ciência-Tecnologia-Sociedade (CTS), ambas balizadas na utilização de temas/problemas de relevância social. No entanto, a prática ainda continua sendo pautada por pequenas intervenções, uma vez que o currículo da instituição ainda permanece focado em referenciais tradicionais de instâncias superiores, como o programa do vestibular da Universidade Federal de Santa Maria (UFSM).

Como consequência dessa positiva mudança na concepção curricular, o processo de ensino/aprendizagem foi potencializado, visto que houve maiores participação e interação entre aluno-aluno e aluno-professor. Isso, porém, será foco da próxima categoria.

\section{O diálogo entre professor-aluno e aluno-aluno}

Nesta categoria, de forma unânime, os professores discorreram sobre a importância que o diálogo tem para aproximar professor-aluno e aluno-aluno, principalmente quando se realiza um trabalho com temas. Já nos relatos anotados nos diários, foi possível observar essas aproximações, como nos relatos abaixo, representativos do conjunto:

Percebi que a maioria dos alunos estão se aproximando mais de mim e também perguntando mais depois de começar a trabalhar com o tema. (Prof. 2)

Parece que agora, depois de avaliar o trabalho com a abordagem temática, os alunos perderam o medo de dialogar entre si e comigo, sinto eles mais próximos de mim. (Prof. 3)

Ressalta-se, no entanto, que a palavra “diálogo" assumida nesse contexto está em sintonia com os pressupostos de Paulo Freire. Ele defende que esse "diálogo" não é um diálogo qualquer, ou seja, não é puro e simplesmente "palavreria, verbalismo, blá-blá-blá" (FREIRE, 1987. p. 44). Desse modo, Freire (1968, p. 44) assim define diálogo:

E que é o diálogo? É uma relação horizontal de A com B. Nasce de uma matriz crítica e gera criticidade [...]. Nutre-se do amor, da humildade, da esperança, 
da fé, da confiança. Por isso, só o diálogo comunica. E quando os dois polos do diálogo se ligam assim, com amor, com esperança, com fé um no outro, se fazem críticos na busca de algo. Instala-se, então, uma relação de simpatia entre ambos. Só aí há comunicação.

Dessa forma, o diálogo é conceito-chave por meio do qual professor e aluno se tornam sujeitos atuantes e é também prática essencial na concepção freireana. Para Freire, o diálogo não é apenas um método, mas uma estratégia para respeitar o saber do aluno que chega à escola.

Para exemplificar esta categoria, citam-se algumas falas de professores, manifestadas no questionário, representativas do conjunto:

Trabalhar com temas fez-me aproximar mais dos alunos, tanto no diálogo como na troca de ideias. (Prof. 8)

Antes eu me sentia apenas um professor repassador do conbecimento, agora, com a abordagem temática e depois de ter aumentado o diálogo com os alunos, vejo que também aprendo com eles e eles aprendem entre si. (Prof. 6)

Em consonância com isso, Delizoicov, Angotti e Pernambuco (2011) abordam o diálogo como mediador entre as demandas afetivas e cognitivas de professores e alunos num projeto coletivo. Assim, na perspectiva dos autores, por meio do diálogo,

[...] a sala de aula passa a ser espaço de trocas reais entre os alunos e entre eles e o professor, diálogo que é construído entre conhecimentos sobre o mundo onde se vive e que, ao ser um projeto coletivo, estabelece a mediação entre as demandas afetivas e cognitivas de cada um dos participantes. (DELIZOICOV; ANGOTTI; PERNAMBUCO, 2011, p. 153)

Para aprofundar esta categoria, é importante comentar que, na entrevista, a maioria dos professores também relatou a importância do diálogo na aproximação deles com os alunos, conforme manifestado nos seguintes excertos, representativos do conjunto:

[...] No inicio, eles [alunos] sentavam e esperavam que eu dissesse o que fazer. Ao longo do tempo, eles chegavam e diriam: "Professora isso não dá, não deu! E aí? Mas, a intenção é faz̧er... de tal jeito, a gente tomou essa decisão. Dá para ser assim? A senhora, acha o quê??... Que dá para fazer?" Foi dai que eu percebi que a partir do tema, en me aproximei muito deles. [...] A gente ia dialogando e eles [os alunos] iam tendo mais liberdade e autonomia para decidirem o que fazer [...] assim com esta aproximação e com este diálogo foi muito bom, porque tu vai junto com eles, tu caminha junto, te coloca no mesmo patamar que eles, porque, tu, também, está aprendendo [...]. (Prof. 2)

[...] A partir do momento em que o aluno, durante a pesquisa de um tema, dava pra gente ver que ele se transformou. Quando eu me reunia, no turno inverso, quando fazia atividades, ele não era mais meu aluno apenas, ele era meu colega de pesquisa, pois eu trocava ideias com ele. Sabe, deu pra ver, tranquilamente, uma aproximação, um diálogo diferenciado entre nós [professor e aluno] [...]. (Prof. 4) 
[...] O trabalho com as temáticas foi muito valioso. Muito mais válido, do que dar uma aula tradicional, comum, porque ali os alunos puderam se aproximar e dialogar mais com o professor, [...] foi-se a época que o professor era colocado num pedestal, né? [...] Percebo, assim, nesses momentos de aproximação, de diálogo, que é uma coisa, assim, muito calorosa, é muito mais bumana, [...] ele [aluno] teve a oportunidade de colocar seus problemas, suas dúvidas, compartilhar ideias com seus colegas e com professores [...]. (Prof. 5)

[...] Sim, ele [aluno] procura mais, ele traz, ele vem pedir a tua opinião e ele traz sugestões e, tu... E tu acaba ah... Te interessando, por assuntos, que, às vezes, tu não tinha nem pensado, que são da realidade deles [...] Existe esta aproximação, quando se trabalha com tema, realmente, os alunos se aproximam de ti e, tu se aproxima mais dos alunos, e eles te desafiam, ai tu vai ver como é importante manter este diálogo aberto e franco com eles [...]. (Prof. 8)

Destaca-se, a partir desses excertos, que a maioria dos professores conseguiu perceber o quanto o diálogo entre professoraluno e aluno-aluno é importante na implementação das temáticas. Isso ficou evidenciado pelos seguintes apontamentos: a partir do tema, o professor se aproximou mais de seus alunos; professor e aluno iam dialogando, caminhando juntos, compartilhando ideias; o professor se colocava no mesmo patamar do aluno; o professor considerava o aluno não mais apenas como "aluno", mas como seu colega de pesquisa; os alunos dialogavam abertamente e francamente entre si e com os seus professores. Ressalta-se, portanto, a partir dessas evidências, a importância fundamental do papel do professor como um construtor do conhecimento entre professor-aluno e aluno-aluno por meio de um processo dialógico franco e aberto.

No que tange a isso, citam-se Sampaio, Quadrado e Pimentel (1994, p. 62-63) ao discorrerem sobre a metodologia dialógica proposta no Projeto de Interdisciplinaridade via Tema Gerador. Os autores afirmam que o diálogo é a ferramenta essencial e deve pautar as interações entre todos os elementos participantes do processo, devendo se dar na práxis ação-reflexão.

Corroborando nesse sentido, Pernambuco (2002) discorre que o diálogo em sala de aula é importante, pois facilita o trabalho do professor e aumenta o interesse dos alunos por determinados assuntos/temas. Para ela, o diálogo é um fator essencial na interação e no movimento do grupo, além de exigir o respeito ao pensamento do outro e estabelecer comunicação. Isso, segundo ela, é incisivo para haver a construção do conhecimento.

Enfim, fica compreendido, a partir desta categoria, que o diálogo entre professor-aluno e aluno-aluno é ferramenta essencial e potencialmente promissora no processo de ensino/aprendizagem e na construção e na implementação da abordagem temática na prática escolar. 


\section{CONSIDERAÇÕES FINAIS}

Este estudo abordou a implementação da abordagem temática na prática educativa de uma escola pública estadual do interior do Rio Grande do Sul. Envolveu seus educadores tanto do Ensino Médio regular quanto da EJA, almejando contribuir para a ampliação e o fomento das discussões de novas estratégias de pesquisa e ensino dentro da área de Educação em Ciências.

Analisaram-se, assim, os possíveis avanços alcançados pelos professores da escola pesquisada quando implementaram intervenções curriculares na perspectiva da abordagem temática para turmas do Ensino Médio regular e da EJA. Entre os aspectos analisados e discutidos estiveram: o tema trabalhado a partir da realidade, do contexto do(s) aluno(s); a mudança na concepção de currículo; e o diálogo entre professor-aluno e aluno-aluno.

Quanto à primeira categoria - o tema trabalhado a partir da realidade, do contexto do(s) aluno(s) -, ressalta-se que a maioria dos professores percebeu que, para concretizar a construção de um projeto curricular cuja ênfase esteja na abordagem temática, é preciso levar seriamente em conta a realidade social, econômica, política e cultural dos alunos. Desse modo, é necessário fazer análises, reflexões, ouvir várias opiniões, buscar entender a história dos lugares em relação à história do mundo e, assim, mergulhando na própria realidade, construir e reconstruir o projeto curricular de cada escola, pois, quanto mais conseguirmos aprofundar nossos conhecimentos sobre a realidade, mais nos tornaremos sujeitos ativos e construiremos condições para transformá-la.

$\mathrm{Na}$ segunda categoria - a mudança na concepção de currículo -, salienta-se que a maior parte dos professores conseguiu mudar sua concepção de planejamento curricular, uma vez que as temáticas construídas e implementadas por eles foram favorecidas por uma constante (re)construção de parâmetros curriculares mais abertos e flexíveis, em oposição ao paradigma curricular linear vigente, baseado numa prática prescritiva em que subjazem as instâncias que estão fora da escola. Nesse sentido, defende-se um currículo que não seja aprisionado em algumas folhas de papel e meticulosamente descrito, mas um currículo que represente a realidade e na vida de educando e de educador se inspire, ou seja, que expresse interesses humanos, políticos, culturais e sociais, exprimindo nosso poder para reconstruir a vida social, participar na comunicação, na tomada de decisões e na ação social.

Já na última categoria - o diálogo entre professor-aluno e aluno-aluno -, destaca-se que a maioria dos docentes depreendeu 
o quanto é relevante o papel do professor como construtor do conhecimento entre professor-aluno e aluno-aluno por meio de um processo dialógico autêntico baseado na inspiração freireana. Ressalta-se, desse modo, que esse processo dialógico conduziu, de forma marcante, as atividades de implantação da abordagem temática no cotidiano da escola supramencionada e as ações dos professores em sala de aula. Deve-se, nesse sentido, fomentar a vivência de um diálogo autêntico e crescente entre educadores, entre educadores e educandos, entre educandos e educandos, a fim de que o saber e o aprender sejam criados e recriados nestes e naqueles.

É importante frisar que todas essas categorias contribuem na mudança para o novo estilo de pensamento curricular calcado na abordagem temática, uma vez que estão em consonância com o profundo processo de reconfigurações curriculares balizadas na perspectiva crítica e no contexto social.

Ressalta-se, portanto, a abordagem temática como uma das possibilidades didático-pedagógicas promissoras para minimizar os principais problemas e limitações do contexto escolar. Nesse processo, também se destacam, como analisado, adotar uma organização curricular capaz de produzir uma articulação interdisciplinar entre os conteúdos programáticos e os temas abordados, construir ações investigativas e problematizações dos temas estudados, levar o aluno a pensar de forma articulada e contextualizada com sua realidade e fazer com que ele possa ser protagonista do processo de ensino/aprendizagem.

\section{REFERÊNCIAS}

AULER, D. Enfoque Ciência-Tecnologia-Sociedade: pressupostos para o contexto brasileiro. Ciência \& Ensino, Piracicaba (SP), v. 1, n. especial, p. 1-20, 2007.

- Interações entre ciência-tecnologia-sociedade no contexto da formação de professores de ciências. 2002. 248 f. Tese (Doutorado em Educação: Ensino de Ciências Naturais) - Centro de Ciências da Educação, Universidade Federal de Santa Catarina, Florianópolis (SC), 2002.

. Novos caminhos para a educação CTS: ampliando a participação. In: SANTOS, W. L. P. dos; AULER, D. (Orgs.). CTS e educação científica: desafios, tendências e resultados de pesquisas. Brasília: Editora Universidade de Brasília, 2011. p. 73-97.

BRASIL. Ministério da Educação (MEC), Secretaria de Educação Básica (SEB), Departamento de Políticas de Ensino Médio. Orientações Curriculares Para o Ensino Médio: Ciências da Natureza, Matemática e suas Tecnologias. Brasília: MEC/SEB, 2008.

. Ministério da Educação e dos Desportos. Parâmetros Curriculares Nacionais. Parte I, II e III. 1999.

CACHAPUZ, A. et al. A necessária renovação do ensino das ciências. 2. ed. São Paulo: Cortez, 2011. 
DELIZOICOV, D.; ANGOTTI, J. A. P.; PERNAMBUCO, M. M. C. Ensino de Ciências: Fundamentos e Métodos. 4. ed. São Paulo: Cortez, 2011.

FERRAZ, L. N. C. V. M. Metodologia do Ensino das Ciências: Concepção e Avaliação de uma Acção de Formação Contínua para Professores numa Perspectiva CTS. Tese (Doutoramento em Educação) - Instituto de Educação e Psicologia, Universidade do Minho, Portugal, 2009.

FERREIRA, L. A. G. Abordagem temática na EJA: sentidos atribuídos pelos educandos a sua educação científica. 2009. 122 f. Dissertação (Mestrado em Educação Tecnológica) - Centro Federal de Educação Tecnológica de Minas Gerais, Belo Horizonte (MG), 2009.

FLECK, L. Gênese e desenvolvimento de um fato científico. Belo Horizonte: Fabrefactum, 2010.

FORGIARINI, M. S.; AULER, D. A abordagem de temas polêmicos na educação de jovens e adultos: o caso do "florestamento" no Rio Grande do Sul. Revista Electrónica de Enseñanza de las Ciencias, Vigo (Espanha), v. 8, n. 2, p. 399-421, 2009.

FREIRE, P. Educação como prática da liberdade. Rio de Janeiro: Paz e Terra, 1968.

Pedagogia da autonomia: saberes necessários à prática educativa. 9. ed. São Paulo: Paz e Terra, 1998.

Pedagogia da esperança: um reencontro com a pedagogia do oprimido. Rio de Janeiro: Paz e Terra, 1992.

Pedagogia do Oprimido. 17. ed. Rio de Janeiro: Paz e Terra, 1987.

FREITAS, A. L. S. Fundamentos, dilemas e desafios da avaliação na organização curricular por ciclos de formação. In: ESTEBAN, M. T. (Org.). Escola, currículo e avaliação. 3. ed. Vol. 2. São Paulo: Cortez, 2008.

GIACOMINI, A.; MAGOGA, T. F.; MUENCHEN, C. O cultivo do arroz: implementação e alguns resultados no ensino de física. In: SEMINÁRIO INTERNACIONAL DE EDUCAÇÃO EM CIÊNCIAS, 2. Rio Grande. Anais eletrônicos... Rio Grande: FURG, 2012. Disponível em: <http://www.sintec.furg.br/index.php?option=com_ phocadownload\&view $=$ category\&id=1\&Itemid $=54>$. Acesso em: 26 abr. 2014.

GIACOMINI, A.; MUENCHEN, C.; MAGOGA, T. F. Uma intervenção curricular baseada na abordagem temática: o caso do cultivo do arroz. Enseñanza de Las Ciencias, Barcelona (Espanha), n. extra, p. 2452-2456, set. 2013. Disponível em: <http://congres.manners.es/ congres_ciencia/gestio/creacioCD/cd/articulos/art_360.pdf>. Acesso em: 2 maio 2014.

GIL, A. C. Métodos e técnicas de pesquisa social. 5. ed. São Paulo: Atlas, 2007.

GÜNTHER, H. Pesquisa Qualitativa Versus Pesquisa Quantitativa: esta é a questão? Psicologia: Teoria e Pesquisa, v. 22, n. 2, p. 201-210, 2006.

HALMENSCHLAGER, K. R. Abordagem Temática no Ensino de Ciências: Algumas Possibilidades. Vivências: Revista Eletrônica de Extensão da URI, Erechim (RS), v. 7, n. 13, p. 10-21, 2011.

LUCATTO, L. G.; TALAMONI, J. L. B. A construção coletiva interdisciplinar em educação ambiental no ensino médio: a microbacia hidrográfica do ribeirão dos peixes como tema gerador. Ciência \& Educação, Bauru (SP), v. 13, n. 3, p. 389-398, 2007.

MARCONDES, A. P.; ACOSTA, S. F. Abordagem qualitativa: a etnografia. Parte I. In: CENTRO de Referência Virtual do Professor. Minas Gerais: Secretaria de Estado de educação. 2006. Disponível em: <http://crv.educacao.mg.gov.br/sistema_crv/index. aspx?ID_PROJETO $=27 \& I D \_O B J E T O=32502 \&$ tipo $=o b \& c p=000000 \& c b=>$. Acesso em: 7 fev. 2013. 
MARTINS, I. P. Formação inicial de professores de física e química sobre a tecnologia e suas relações sociocientíficas. Revista Electrónica de Enseñanza de las Ciencias, Vigo (Espanha), v. 2, n. 3, p. 293-308, 2003.

MARTINS, I. P.; PAIXÃO, M. de F. Perspectivas atuais Ciência-Tecnologia-Sociedade no ensino e na investigação em educação em ciência. In: SANTOS, W. L. P. dos; AULER, D. (Orgs.). CTS e educação científica: desafios, tendências e resultados de pesquisas. Brasília: Editora Universidade de Brasília, 2011. p. 135-160.

MORAES, R.; GALIAZZI, M. C. Análise Textual Discursiva. Ijuí: Ed. Unijuí, 2007. 224 p.

MUENCHEN, C. A disseminação dos três momentos pedagógicos: um estudo sobre práticas docentes na região de Santa Maria/RS. 2010. 273 f. Tese (Doutorado em Educação) - Centro de Educação, Universidade Federal de Santa Catarina, Florianópolis (SC), 2010.

Configurações curriculares mediante o enfoque CTS: desafios a serem enfrentados na EJA. Santa Maria: PPGE/CE/UFSM, 2006. Dissertação (Mestrado em Educação) - Universidade Federal de Santa Maria, 2006.

MUENCHEN, C.; DELIZOICOV, D. Os Três Momentos Pedagógicos: um olhar históricoepistemológico. In: ENCONTRO DE PESQUISA EM ENSINO DE FÍSICA, 12, 2010. Atas... Águas de Lindoia/SP, 2010.

NASCIMENTO, T. G.; VON LINSINGEN, I. Articulações entre o enfoque CTS e a pedagogia de Paulo Freire como base para o ensino de ciências. Convergencia, Toluca (Estado do México), v. 13, n. 42, p. 95-116, 2006.

PÉREZ GÓMEZ, A. I. A função e formação do professor/a no ensino para a compreensão: diferentes perspectivas. In: GIMENO SACRISTÁN, J.; PÉREZ GÓMEZ, A. I. Compreender e transformar o ensino. 4. ed. Cap. 11. Porto Alegre (RS): Artmed, 1998. p. 353-379.

PERNAMBUCO, M. M. C. A. Quando a troca se estabelece. In: PONTUSCHKA, N. N. (Org.). Ousadia no diálogo: interdisciplinaridade na escola pública. 4. ed. São Paulo: Loyola, 2002.

SÃO PAULO (cidade). Secretaria Municipal de Educação - SME. Um primeiro olhar sobre o projeto. Cadernos de Formação, n. 1, 1990.

SAMPAIO, M. M. F.; QUADRADO, A. D.; PIMENTEL, Z. P. Interdisciplinaridade no município de São Paulo. Brasília: INEP, 1994.

SANTOS, W. L. P.; MORTIMER, E. F. Uma análise de pressupostos teóricos da abordagem C-T-S (Ciência-Tecnologia-Sociedade) no contexto da educação brasileira. Ensaio: Pesquisa em Educação em Ciências, Belo Horizonte, v. 2, n. 2, p. 1-23, 2002.

SNYDERS, G. A alegria na escola. São Paulo: Manole, 1988.

STRIEDER, R. B. Abordagens CTS na educação científica no Brasil: sentidos e perspectivas. 283 f. Tese (Doutorado em Ensino de Física) - Universidade de São Paulo, São Paulo, 2012.

WATANABE-CARAMELLO, G.; STRIEDER, R. B. Elementos para desenvolver abordagens temáticas na perspectiva socioambiental complexa e reflexiva. Revista Electrónica de Enseñanza de las Ciencias, Vigo (Espanha), v. 10, n. 3, p. 587-608, 2011.

\section{NOTAS}

${ }^{1}$ Trata-se de um nome fictício para o município, e não real. A letra " $\mathrm{X}$ " foi usada em substituição ao nome real em todas as menções neste artigo. 
${ }^{2}$ Trata-se de um nome fictício para a escola, e não real. A letra "Y" foi usada em substituição ao nome real em todas as menções neste artigo.

${ }^{3}$ Trata-se de um nome de município fictício, e não real.

${ }^{4}$ Trata-se de um nome de município fictício, e não real.

Submetido: 07/06/2014

Aprovado: 12/01/2016

Contato:

Rua Br 158, n 260, Bl. K2, Ap. 206, Residencial Arco Verde, Bairro Boi Morto, Santa Maria|RS|Brasil

CEP: 97.030-620. 